\title{
Rives Technique for the Primary Larger Inguinal Hernia Repair: A Prospective Study of 1000 Repairs
}

\author{
Enrique J. Grau-Talens ${ }^{1,8} \cdot$ Carlos D. Ibáñez ${ }^{2} \cdot J^{2}$ acob Motos-Micó ${ }^{3} \cdot$ \\ Francisco García-Olives ${ }^{4}$ - Martina Arribas-Jurado ${ }^{5}$ - Carlos Jordán-Chaves ${ }^{6}$. \\ José M. Aparicio-Gallego ${ }^{7} \cdot$ José F. Salgado $^{2}$
}

Published online: 8 May 2017

(C) The Author(s) 2017. This article is an open access publication

\begin{abstract}
Objective We report a prospective study of repairs using the Rives technique of the more difficult primary inguinal hernias, focusing on the immediate post-operative period, clinical recurrence, testicular atrophy, and chronic pain. A mesh placed in the preperitoneal space can reduce recurrences and chronic pain.

Methods For the larger primary inguinal hernias (Types 3, 4, 6, and some 7), we favour preperitoneal placement of a mesh, covering the myopectineal orifice by means of a transinguinal (Rives technique) approach. The Rives technique was performed on 943 patients (1000 repairs), preferably under local anaesthesia plus sedation in ambulatory surgery.

Results The mean operative time was $31.8 \mathrm{~min}$. Pain assessment after $24 \mathrm{~h}$ with an Andersen scale and a categorical scale gave two patients with intense pain on the Andersen scale, and four patients who thought their state was bad. Surgical wound complications were below $1 \%$, and urinary retention was $1.2 \%$ mostly associated with spinal anaesthesia and, in one case, bladder perforation. There was spermatic cord and testicular oedema with some degree of orchitis in 17 patients. The clinical follow-up of 849 repairs (86.4\%), mean (range) 30.0 (12-192) months, gave five recurrences $(0.6 \%)$, three cases $(0.4 \%)$ of testicular atrophy, and $37(4.3 \%)$ of post-operative chronic pain $(8$ patients with visual analogue scale of 3-10).

Conclusions The Rives technique requires a sound knowledge of inguinal preperitoneal space anatomy, but it is an excellent technique for the larger and difficult primary inguinal hernias, giving a low rate of recurrences and chronic pain.
\end{abstract}

Enrique J. Grau-Talens

ejgtalens@yahoo.es

Carlos D. Ibáñez

cdibanez@hotmail.com

Jacob Motos-Micó

Jacob_motos@hotmail.com

Martina Arribas-Jurado

corchua85@hotmail.com

Carlos Jordán-Chaves

makijordan@hotmail.com

José M. Aparicio-Gallego

josemariaparicio@hotmail.com
José F. Salgado

josefesalgado@hotmail.com

1 Hospital Siberia-Serena, Carretera Talarrubias-Agudo, SN, 06640 Talarrubias, Badajoz, Spain

2 Hospital Siberia-Serena, Calle Zafra, 3, 3D, 06400 Don Benito, Badajoz, Spain

3 Hospital Siberia-Serena, Calle Canaleja, 4, $2^{\circ}$ A, 06400 Don Benito, Badajoz, Spain

4 Verge Del Toro Hospital, Menorca. Fort de L'eau 96, 07701 Mahón, Balearic Islands, Spain 


\section{Introduction}

The value of a surgical intervention lies in the short and long term results (quality) provided at a reasonable cost [1]. The primary repair of an inguinal hernia aims to cure the symptoms and prevent immediate post-operative complications, chronic pain, and recurrences. Mesh repair has reduced the recurrence of inguinal hernias, but there is still a rate of $4 \%$ of recurrence and $12 \%$ of post-operative chronic pain, moderate-to-severe, with the Lichtenstein procedure [2].

The aim of our work is the prospective study of the Rives technique for repair of the larger primary inguinal hernias (transinguinal insertion of a mesh in the preperitoneal space), focusing on the immediate postoperative period, clinical recurrence, and chronic pain. The mesh placed in the preperitoneal space, covering the myopectineal orifice of Fruchaud and separated from the neurological plane, is the ideal location hydrostatically and anatomically to prevent the recurrence of the three potential hernia orifices and chronic pain.

\section{Patients and methods}

From January 1992 to April 2014, we performed 1000 primary inguinal hernia repairs in 943 patients using the Rives technique: 198 patients at the Verge del Toro Hospital, Mahon, Menorca (Balearic Islands), Spain (1992-2001); and 745 patients from October 2007 until April 2014 in ambulatory/short-stay surgery at the SiberiaSerena Hospital, Talarrubias (Badajoz), Spain. In 1994, all the data of the operated patients, which had been collected in paper form, were input into an Access-form database. All data collected thereafter were input into the said database on a daily basis and analysed with Excel.

Between 2001 and 2006, the first author did not perform abdominal wall surgery because he was assigned to the coloproctology section of the Infanta Cristina University Hospital, Badajoz, Spain.

5 Calle La Cola, 10, 14300 Villaviciosa de Córdoba, Córdoba, Spain

6 Hospital Siberia-Serena, Calle Santiago, 32, 06900 Llerena, Badajoz, Spain

7 Calle $1^{\circ}$ de mayo, $71,4^{\circ}, 06400$ Don Benito, Badajoz, Spain

8 Calle Castillo 15, 06006 Zalamea de la Serena, Badajoz, Spain
Inclusion criteria and perioperative measures and follow-up

We use Gilbert's classification with additions by Rutkow and Robbins [3]. The Rives technique was used in Types 2 (when the deep inguinal ring was about $4 \mathrm{~cm}$ in diameter), $3,4,6$, and some of the 7 .

In ambulatory surgery, all patients are contacted via telephone within $24 \mathrm{~h}$ of surgery and pain is evaluated at rest and mobilization using the Andersen scale [4]. This is concluded with a subjective assessment by the patient on a categorical scale of bad, fair, good, or excellent overall condition. After a week they are called again.

The first 467 patients were clinically reviewed in the office within 7-10 days of discharge (for the rest of the patients, we opted for telephone inquiry to spare them from coming to the hospital, where the wound was observed, and pain was evaluated at rest and with movement (standing up, sitting down, and walking), using a VAS (visual analogue scale) in 154 consecutive patients, as a representative sample size for post-operative pain.

They are reviewed clinically by the service's surgeons again after a year or earlier if the patient experiences pain, and called again 3 or more years later. If pain is found, this is evaluated as being with movement, spontaneous, episodic, or constant in nature, and measured with a VAS. The inguinal region is examined. A mass, reducible or otherwise, is regarded as a recurrence. Testicular examination is made for atrophy or other pathology, and inquiry for late infection.

Preoperative preparation includes the prophylaxis of nausea and vomiting with dexamethasone $8 \mathrm{mg}$ IV. Prophylaxis of the surgical site infection (cefazoline $2 \mathrm{~g} I V$ ) is not performed routinely. It was done in obese, diabetics, and bilateral hernia repair. Glove change and wound protection with gauze before inserting the mesh were the rule. Lastly, rinsing wound preceded the skin sutures.

\section{The technique now}

We perform the technique preferably under local anaesthesia and sedation, with mepivacaine $1 \%, 400-500 \mathrm{mg}$ $(6 \mathrm{mg} / \mathrm{kg})$ according to the technique of Ponka and Flanagan [5]. An anaesthesiologist provides sedation. The sedation begins with midazolam $(0.03 \mathrm{mg} / \mathrm{kg} \mathrm{IV})$ followed by propofol $(25-50 \mathrm{mc} / \mathrm{kg} / \mathrm{min})$. Upon finishing the intervention, we infiltrate the surgical field with $20-30 \mathrm{ml}$ of $0.25 \%$ bupivacaine. In very large inguinoscrotal or nonreducible hernias, spinal or general anaesthesia is used.

The surgical technique comprises the insertion of a mesh in the preperitoneal space through the groin as described by Rives [6-10]. We use a $15 \times 15 \mathrm{~cm}$ polypropylene mesh (standard weight $80 \mathrm{~g} / \mathrm{m}^{2}$, and macro-porous 


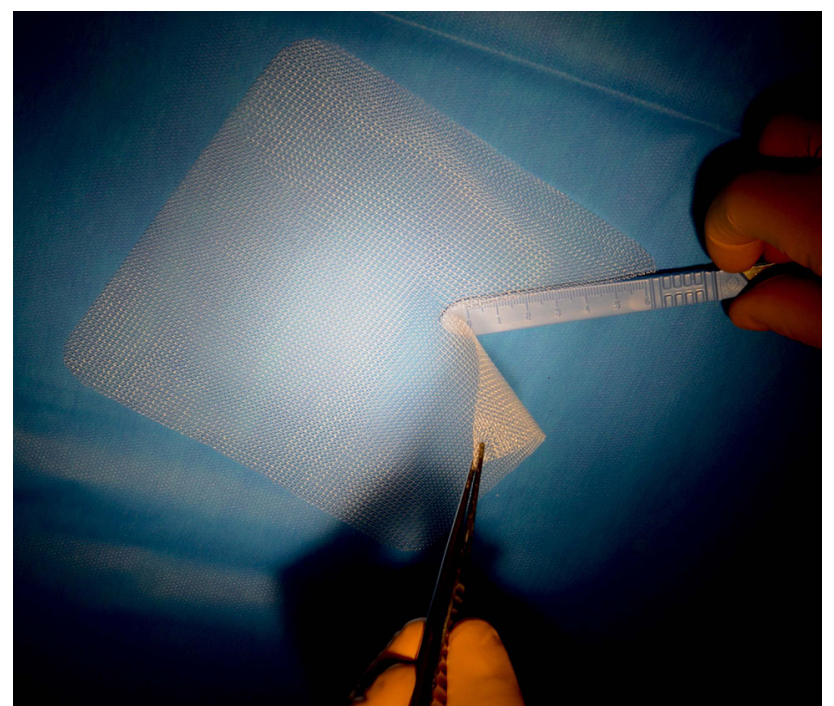

Fig. 1 Slit for the spermatic cord

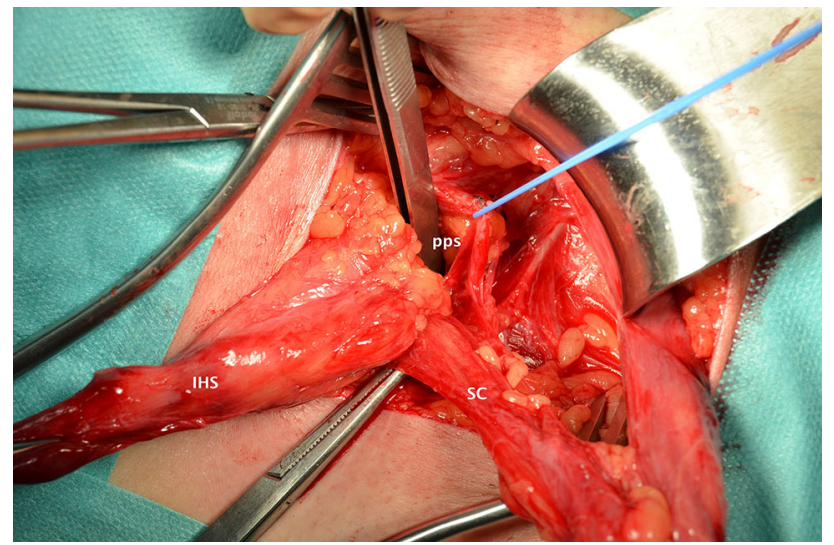

Fig. 2 DIR (deep inguinal ring) is dissected. A vessel loop is pulling the inferior epigastric vessels. Forceps are in the preperitoneal space (PPS). IHS indirect hernial sac. SC spermatic cord

$0.5 \times 0.7 \mathrm{~mm})$ in which we make a slit for the passage of the spermatic cord (Fig. 1). We have made some modifications over the years, but we remain faithful to the principles of the technique.

An incision of 6-8 $\mathrm{cm}$ in length is made in the medial $2 / 3$ of the line from the anterior superior iliac spine to the pubic tubercle. The ilioinguinal, iliohypogastric, and genital branch of the genitofemoral nerve are preserved. The cremaster is not removed, but opened longitudinally and split to separate the fibres along with the external spermatic vessels (blue line) [10,11] and the genital branch of the genitofemoral nerve. The spermatic cord, without the cremaster, is lifted and held with a rubber band. The internal spermatic fascia is opened up to the preperitoneal fat (space of Bogros), and the indirect sac (and lipomata) is dissected

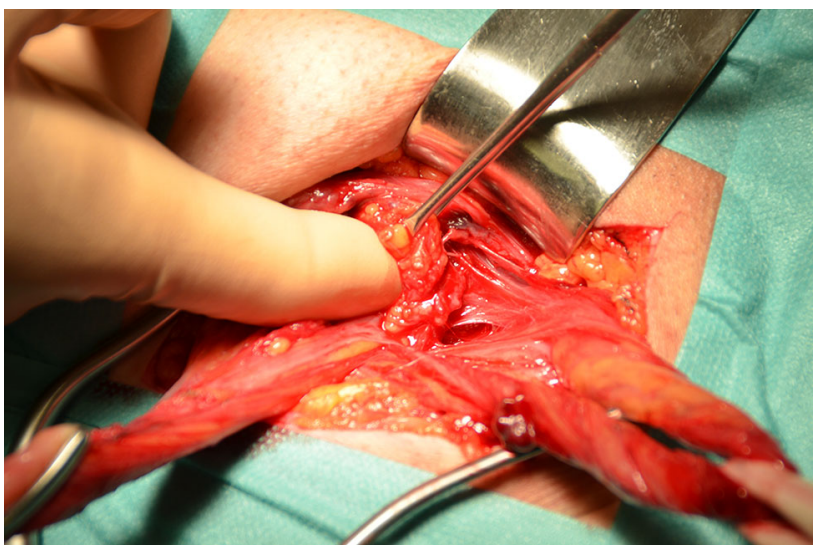

Fig. 3 Preperitoneal space for mesh accommodation is created with the finger

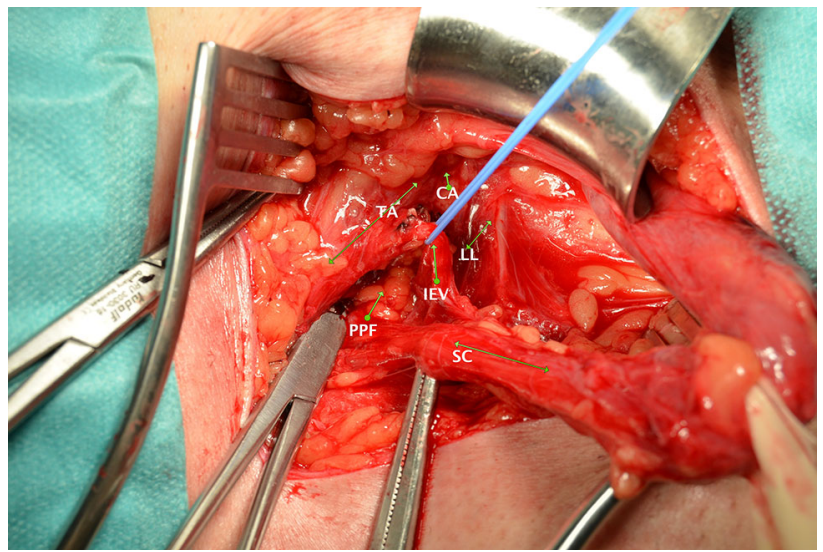

Fig. 4 Anatomic vision of the DIR in an indirect large hernia. The indirect hernia sac is already reduced. $T A$ transversus abdominis arch. $C A$ conjoined area. $L L$ lacunar ligament. $I E V$ inferior epigastric vessels. $S C$ spermatic cord. $P P F$ Preperitoneal fat

up to the peritoneal level (true neck) in the deep inguinal ring (DIR) [12] and reduced to the iliac fossa (Fig. 2).

Indirect hernia At the medial edge of the DIR are the inferior epigastric vessels displaced medially, and posterior to them and to the transversalis fascia (Retzius space) we create a space, by sharp and blunt dissection, to accommodate the mesh (Figs. 3, 4). Cooper's ligament can be seen, and the femoral orifice is explored for a femoral hernial sac. The mesh is introduced through the DIR with a stitch passed through the conjoined tendon, emerging through the DIR posterior to the inferior epigastric vessels, and taking the mesh with it as it returns, coming out again through the conjoined tendon (Fig. 5).

In direct hernias (the DIR is explored for an indirect sac) the attenuated transversus abdominis aponeurosis and transversalis fascia over the direct sac are opened transversally to enter the preperitoneal space. A femoral 


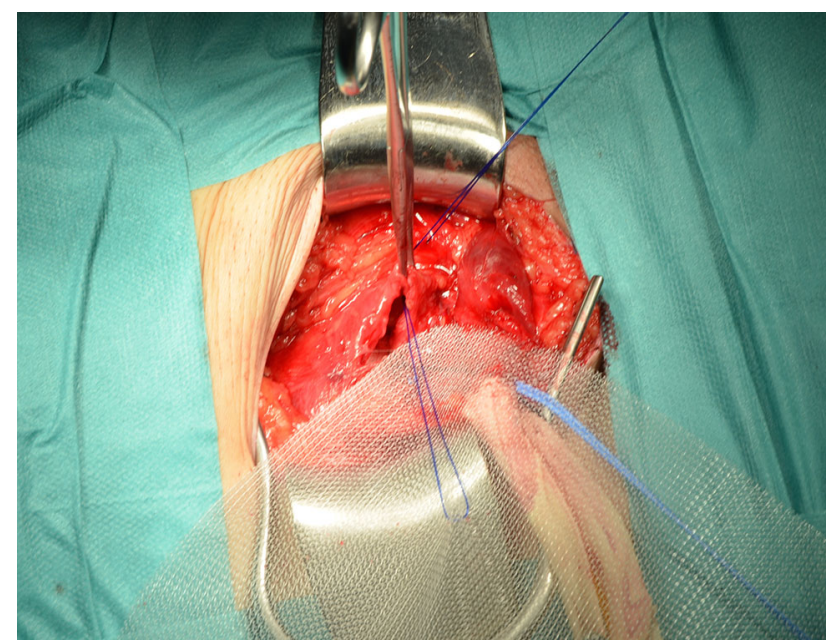

Fig. 5 Mesh ready to be passed under epigastric vessels to lie under conjoined area. A stitch running through the conjoined area near the pubic tubercle, coming out through the DIR under the inferior epigastric vessels, takes the mesh and returns the same way it came to the conjoined area

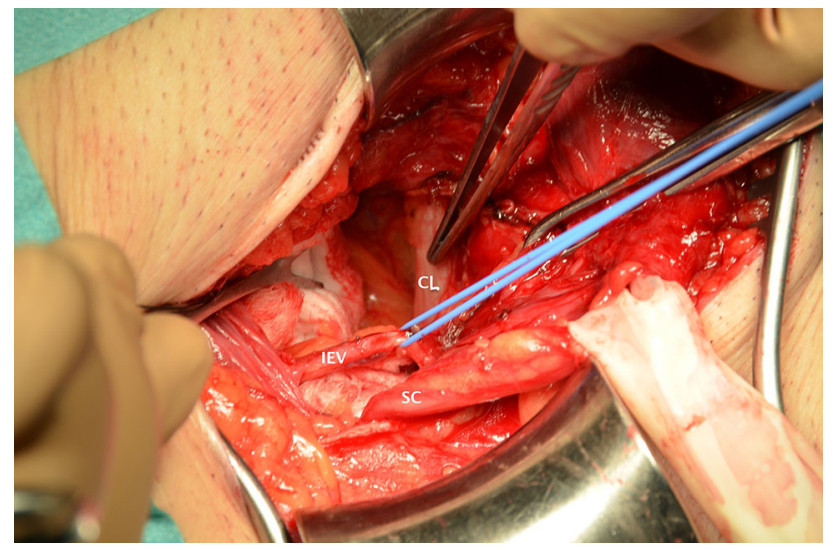

Fig. 6 Transversalis fascia over a direct sac has been opened and the hernia reduced. A wound swab is introduced. Forceps are pointing at the Cooper ligament (CL). Inferior epigastric vessels (IEV) are pulled by a vessel loop. The spermatic cord (SC) is held with a rubber band

sac, if any, is reduced. The inferior epigastric vessels are released and preserved (Fig. 6), and the mesh, inserted through Hesselbach's triangle, slides (preferably) under them or pushes them down and overlies them (less desirable case) [13].

Mesh fixation The mesh is fixed with 5-7 stitches of polypropylene monofilament with an appropriate needle (premilene ${ }^{\circledR}$ No. 0, HR80, B Braun). The first stitch in the conjoined tendon (as described above) acts as an anchor. The second stitch takes the Cooper's ligament (close to the femoral ring) and the mesh, at approximately $4 \mathrm{~cm}$ from the edge (Fig. 7), slid over it and covering the femoral and obturator rings. Particular attention has to be paid to the anastomotic pubic branch, and sometimes to the anterior

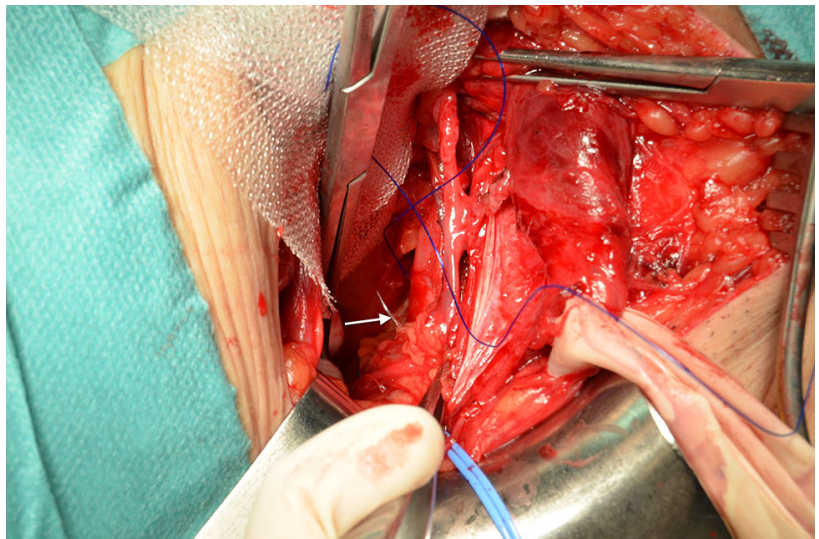

Fig. 7 A stitch (white arrow) is passed through Cooper ligament

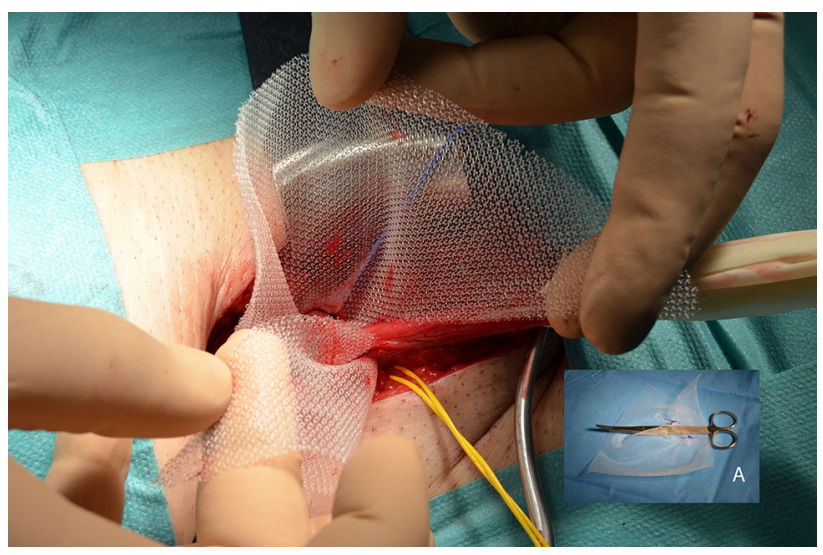

Fig. 8 Spermatic cord is positioned in the slit and a tunnel-like flap is made around it, as seen in the lower image A

pubic branch artery, obturator accessory, or aberrant artery and corresponding veins. In indirect hernias, due to the limited space of the DIR, it is easier to put the stitch into the Coopeŕs ligament before mesh introduction and fixation to the posterior face of the conjoined tendon. If access to the Cooper ligament is difficult, the mesh is attached to the iliopubic tract (less desirable), with care taken of the inferior epigastric vessels.

The spermatic cord is positioned in the slit of the mesh, and wrapped with it in the manner of a tunnel (Fig. 8). The mesh is slipped with Crile forceps behind the transversus abdominis muscle in the preperitoneal space. The third stitch fixes the mesh to the vascular fascia/iliopubic tract, taking care with the genital branch of the genitofemoral nerve, the fourth stitch is placed into the transversus abdominis arch, and the fifth into the most lateral zone of the transverse arch. Additional sutures are inserted if needed. The mesh covers and exceeds entirely, by at least $4 \mathrm{~cm}$, the myopectineal orifice (Fig. 9). 


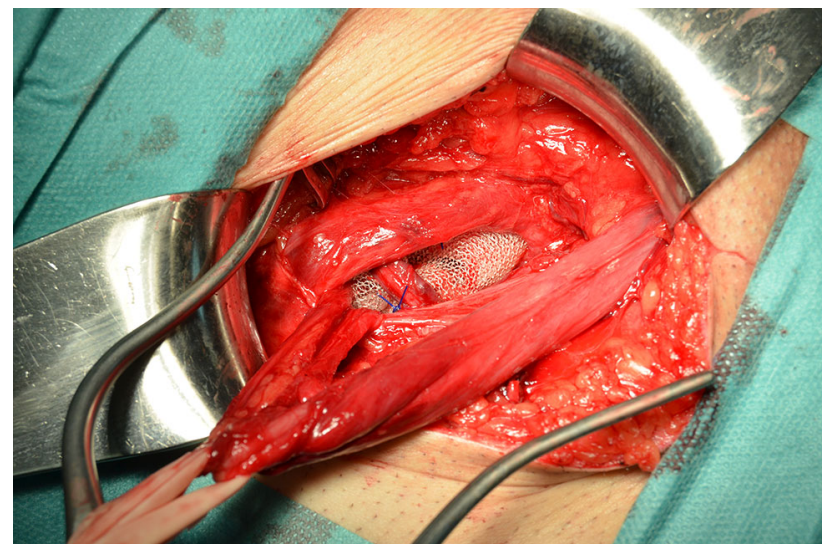

Fig. 9 Mesh is in the preperitoneal space covering the whole myopectineal orifice in a type 6 (pantaloon) hernia

\section{Results}

The demographic and operative findings are presented in Tables 1 and 2. Pain assessment after $24 \mathrm{~h}$ in 761 consecutive unilateral repairs in ambulatory surgery (Table 3 ) revealed two patients with intense pain, while four patients referred to a bad state due to coughing (1), wound pain and testicular oedema (2), and urinary retention (1).

The results of the VAS evaluation in the office 1 week after the intervention in 154 consecutive patients were 0.5 (1.5) at rest, and 2.7 (2.1) in movement [mean (SD)].

Surgical wound complications (Table 4) were below $1 \%$. One patient suffered post-operative hypotension with a drop in haemoglobin levels and was re-operated with the finding of a large bleeding hernial sac without associated vascular lesion. One bladder perforation occurred due to an unusual adherence of the bladder to a fibrotic DIR. Spermatic cord and testicular oedema with some degree of

Table 1 Demographics of the primary inguinal hernia patients with Rives technique repair

\begin{tabular}{ll}
\hline Number of repairs & 1000 \\
Number of patients & 943 \\
Women/men & $56 / 887$ \\
Age, mean (range) years & $60.2(18-93)$ \\
Body mass index, mean (SD) & $28.2(3.7)$ \\
$\mathrm{BPH}^{\mathrm{a}}, n(\%)$ & $164(18.4 \%)$ \\
$\mathrm{COPD}^{\mathrm{b}}, n(\%)$ & $68(7.2 \%)$ \\
Right/left & $521 / 479$ \\
Repairs in day-surgery & 785 \\
Bilateral repair-simultaneous $(n$ patients) & 24 \\
Bilateral repair-in two sessions $(n$ patients) & 19
\end{tabular}

\footnotetext{
a Benign prostatic hypertrophy

${ }^{b}$ Chronic obstructive pulmonary disease
}

Table 2 Operative findings in 1000 Rives repairs

\begin{tabular}{lc}
\hline Type $2, n(\%)$ & $36(3.6)$ \\
Type 3, $n(\%)$ & $564(56.4)$ \\
Type 4, $n(\%)$ & $321(32.1)$ \\
Type 6, $n(\%)$ & $45(4.5)$ \\
Type 7, $n(\%)$ & $8(0.8)$ \\
Type 7 with another (direct or indirect), $n(\%)$ & $26(2.6)$ \\
Femoral hole >2 cm, $n(\%)$ & $29(2.9)$ \\
Duration of the intervention, mean (SD) $\min ^{\mathrm{a}}$ & $31.8(7.5)$ \\
Type of anaesthesia & \\
General, $n(\%)$ & $8(0.8)$ \\
Spinal, $n(\%)$ & $130(13)$ \\
Local + sedation, $n(\%)$ & $862(86.2)$
\end{tabular}

${ }^{a}$ From incision to the last stitch in the skin

Table 3 Andersen scale and overall categorical status assessment in 761 unilateral repairs in day-surgery at $24 \mathrm{~h}$

\begin{tabular}{ll}
\hline & $N(\%)$ \\
\hline $\begin{array}{l}\text { 0. No pain } \\
\text { 1. Absence of pain at rest, mild with mobilization or }\end{array}$ & $291(38)$ \\
$\quad$ cough & \\
2. Mild at rest or moderate pain with mobilization or & $139(18)$ \\
$\quad$ cough & \\
$\begin{array}{l}\text { 3. Moderate at rest or intense pain with mobilization or } \\
\text { cough }\end{array}$ & $23(3)$ \\
$\begin{array}{l}\text { 4. Intense pain at rest and extreme with mobilization or } \\
\text { cough }\end{array}$ & $1(0.1)$ \\
5. Very intense pain at rest ${ }^{\mathrm{a}}$ & $1(0.1)$ \\
$\begin{array}{l}\text { Excellent, } n(\%) \\
\text { Good, } n(\%)\end{array}$ & $239(32)$ \\
Fair, $n(\%)$ & $456(61)$ \\
Bad, $n(\%)$ & $57(7)$ \\
No reply & $4(0.5)$ \\
\hline
\end{tabular}

a Followed and asymptomatic

b Revised, without any incidents. One patient admitted for bleeding

orchitis was detected in 17 patients. Three patients presented testicular atrophy.

Of the 1000 repairs, 16 patients died in the first year, so that 984 repairs were called for clinical review, and 849 repairs $(86.4 \%)$ were actually clinically reviewed. The overall results of the follow-up are given in Table 5. No late infections of the repair were detected.

The chronic pain measurements registered after 1 year are presented in Table 6. Six patients were treated by infiltration, of whom four had major improvement of the pain. The remaining two needed surgical revision and neurectomy for pain resolution. Currently, there is no patient with severe pain in our series. 
Table 4 Post-operative complications in 1000 Rives technique repairs

\begin{tabular}{|c|c|}
\hline & $N(\%)$ \\
\hline Haematoma $^{a}$ & $7(0.7)$ \\
\hline Seroma & $9(0.9)$ \\
\hline Infection $^{\mathrm{b}}$ & $9(0.9)$ \\
\hline Sinus & $1(0.1)$ \\
\hline Bladder injury & $1(0.1)$ \\
\hline Urinary retention & $12(1.2)$ \\
\hline Testicular pain and swelling & $17(1.7)$ \\
\hline Re-operation ${ }^{\mathrm{c}}$ & $1(0.1)$ \\
\hline Death & 0 \\
\hline
\end{tabular}

${ }^{a}$ Four admitted for observation, and three evacuated and sutured

b One patient with Fournier gangrene

${ }^{c}$ For a larger bleeding hernial sac

Table 5 Overall clinical follow-up of 984 Rives technique repairs

\begin{tabular}{ll}
\hline Followed up, $n(\%)$ & $849(86.4)$ \\
Mean (range), month & $30.0(12-192)$ \\
Median, month & 23 \\
Recurrence, $n(\%)$ & $5(0.6)$ \\
Testicular atrophy, $n(\%)$ & $3(0.4)$ \\
Hydrocele, $n(\%)$ & $6(0.7)$ \\
Pseudocyst of spermatic cord, $n(\%)$ & $5(0.6)$ \\
\hline
\end{tabular}

\section{Discussion}

All surgeons who operate inguinal hernias must have deep knowledge of the inguinal region's anatomy, and this is especially true for the Rives repair technique [12-17].

The preperitoneal space is the most suitable site for the insertion of a mesh [2] because the hydrostatic pressure of the abdominal cavity itself will fix the mesh against the abdominal wall, provided there is sufficient mesh extension $(4 \mathrm{~cm})$ around the hernial ring. There is less intra-abdominal pressure on the mesh if it is located in the preperitoneal space due to the smaller radius (Laplace's law).

The internal spermatic fascia is a continuation of the fascia transversalis [14], and in indirect hernia the dissection of the hernial sac must be prolonged until the preperitoneal fat appears. Medially to the true deep inguinal ring, the inferior epigastric vessels can be seen more or less clearly enveloped in a condensation of transversalis fascia. Sharp dissection, opening the scissor's tip posterior to the epigastric vessels, allows for the exploration of the wall posterior to the transversalis fascia. This sharp dissection is likely to be necessary because the Retzius space is laterally closed along the length of the inferior epigastric
Table 6 Chronic pain at 1 year

\begin{tabular}{lll}
\hline Total, $n(\%)$ & & $37(4.3)$ \\
Pain in movements, $n(\%)$ & & $17(2.0)$ \\
& VAS $^{\mathrm{a}}<3, n$ & 11 \\
& $\mathrm{VAS}=3-6, n$ & 3 \\
& $\mathrm{VAS}=6-10, n$ & 3 \\
Pain episodic spontaneous, $n(\%)$ & & $22(2.5)$ \\
& $\mathrm{VAS}<3, n$ & 21 \\
Pain constant, $n(\%)$ & $\mathrm{VAS}=3-6, n$ & 2 \\
& & $2(0.3)$ \\
\hline
\end{tabular}

${ }^{a}$ VAS visual analogue scale

vessels [16, 18]. The preperitoneal fat must emerge clearly behind the epigastric vessels to allow the exploration, without risk or difficulty, of the Bogros and Retzius spaces.

The inferior epigastric vein and artery are spared. In a few cases of difficult hernias in elderly patients, they were ligated to improve repair. The presence of communicating arteries, aberrant or accessory obturator, which may be as frequent as 30-69\% [19], must be demonstrated by blunt dissection, and, generally speaking, it is easy to avoid puncturing the vessels. Occasionally it is risky to insert a stitch into the Cooper's ligament, and then we settle for the iliopubic tract and the femoral sheath.

The lymphoadipose tissue can simulate the presence of a hernial sac in the femoral canal, and when in doubt we explore the subinguinal region to rule out the presence of a sac in the oval fossa.

Independently of the existence of a clear femoral hernia, the presence of a wide femoral ring arouses suspicions of a future femoral hernia [20]. Nevertheless, given that an epigastric hernia can develop through a ring only a few millimetres wide, the femoral ring's diameter loses importance, while the need to protect it from future hernias with a prosthesis anchored in Cooper's ligament gains in strength.

In Lichtenstein's technique, the femoral ring is strengthened when judged large, while in the Rives technique this is done systematically. Between 7.9 and 40\% [21-23] of the recurrences in an inguinal hernia occur through the femoral ring. Whether they are really recurrences or rather undiscovered hernias is unknown. In any case, Mikkelsen's study's [21] main finding was a 15-fold greater incidence of femoral hernia repair in patients who had previously had an inguinal hernia repair compared with the spontaneous operation rate for a femoral hernia. The rate of recurrences after Lichtenstein's operation is taken by the European Hernia Society [2] to be $4 \%$, although the reality is probably different [24] with a rate twice or thrice that. Even if hernia recurrence has indeed dropped, we still cannot be sure that it is not the main concern in the repair of a primary inguinal hernia. Our recurrence rate of $0.6 \%$ is within the range 
$(0-1.2 \%)$ of those of Read [9], Pélissier et al. [25], and Koning et al. [26, 27]. However, we believe that recurrence should be zero or anecdotal for a technique that covers all potential hernial orifices and turns the slit into a flap for the passage of the spermatic cord avoiding indirect recurrences. The Nyhus posterior preperitoneal prosthetic placement has a similar conception to the transinguinal way and has provided with excellent results when the prosthesis was extended to buttress the abdominal wound [28, 29].

Post-operative chronic pain is defined by the International Guidelines as a pain that was absent prior to the intervention or is different from that prior to the intervention, and lasts for more than 3 months [2]. Franneby et al. [30] found $30 \%$ of inguinal herniorrhaphy patients who reported pain or discomfort and nearly $6 \%$ high-intensity pain with inability to perform daily activities. There is a generalized consensus that identification and protection of the three inguinal nerves lowers the risk of developing severe chronic post-operative pain [11, 30, 31]. From the results of a double-blind, randomized controlled trial, Mui et al. [32] advocated that prophylactic ilioinguinal neurectomy should be incorporated into the essential steps of Lichtenstein hernia repair.

The incidence of chronic pain of any kind in our patients after 1 year was $4.3 \%$ and moderate/severe pain $1.0 \%$. With these results, we can conclude that the polypropylene mesh in preperitoneal position and preservation of the three nerves gives a low chronic post-operative pain rate. However, we needed two neurectomies and four infiltrations for there to be no patient with any pain greater than some mild discomfort.

There are simpler options for inguinal hernia repair than the Rives technique. However, our patients presented hernias through large orifices, with weak walls, and frequently with associated co-morbidity.

Acknowledgements Our sincerest thanks to the extraordinary labour of the Admission Service of the Siberia-Serena Hospital, especially Dr. Félix Miranda, Ms. Guadalupe Díaz, and Ms. Ines Parralejo in citing patients to achieve a high follow-up rate. To the operating room assistant nurses Ms.: Carmen Becerra, Rocío Romero, Lourdes Pérez, Antonia Isabel Cuevas, María José Castro, and Alejandra Alcaide. Finally, to Mr. Carlos J. Grau-Polo for his aid in the preparation of this manuscript. The work is supported by the public service "Servicio Extremeño de Salud" (Extremadure Health Service).

\section{Compliance with ethical standards}

Conflict of interest The authors declare that they have no competing interests.

Open Access This article is distributed under the terms of the Creative Commons Attribution 4.0 International License (http://crea tivecommons.org/licenses/by/4.0/), which permits unrestricted use, distribution, and reproduction in any medium, provided you give appropriate credit to the original author(s) and the source, provide a link to the Creative Commons license, and indicate if changes were made.

\section{References}

1. Traverso LW (1996) Technology and surgery. Dilemma of the gimmick, true advances, and cost effectiveness. Surg Clin North Am 76:129-138

2. Simons MP, Aufenacker T, Bay-Nielsen M et al (2009) European Hernia society guidelines on the treatment of inguinal hernia in adult patients. Hernia 13:343-403

3. Rutkow IM, Robbins AW (1998) Classification systems and groin hernias. Surg Clin North Am 78:117-1127

4. Zaragozá García F, Landa Garcia I, Larrainzar Garijo R et al Normas básicas para un tratamiento adecuado del dolor postoperatorio (2005) In: Dolor Postoperatorio en España. Primer Document Consenso, Imago concept \& Image Development, Madrid, pp 16-24

5. Flanagan L, Bascom JV (1984) Repair of the groin hernia: outpatient approach with local anestesia. Surg Clin North Am $64: 256-267$

6. Rives J (1978) Cure chirurgicale des hernies de ĺaine. Définitions. Objectifs de lintervention. Encyl Med Chir, Paris, Tehniques chirurgicales, appareil digestif, 3.14.02, 40090

7. Rives J, Lardennois B, Hibon J (1978) Traitement moderne des hernies de ĺaine et de leurs récidives. Encycl Med Chir Tech Chir 1(40110):1-12

8. Flament JB, Avisse C, Palot JP, Rives J, The Rives technique: treatment of groin hernias with a mersilene mesh by an inguinal approach (2001) In: Bendavid R et al (eds) Adbominal wall hernias: principles and management. Springer, New York, pp 401-406

9. Read RC, Barone GW, Hauer-Hensen M et al (1993) Properitoneal prosthetic placement through the groin. Sur Clin North Am 73:545-555

10. Grau Talens EJ, Técnica de Rives en la reparación de la hernia inguinal. Reparación protésica preperitoneal total por vía anterior (1997) In: Porrero JL (ed) Cirugía de la pared abdominal. Masson, Barcelona, pp 91-96

11. Alfieri S, Amid PK, Campanelli G et al (2011) Internacional guidelines for prevention and management of post-operative chronic pain following inguinal hernia surgery. Hernia 15:239-249

12. Read RC (2003) Recent advances in the repair of groin herniation. Curr Prob Surg 40:1-80

13. Flament JB, Avisse C, Delattre JF, Anatomy of the abdominal wall (2001) In: Bendavid $R$ et al (eds) Adbominal wall hernias: principles and management. Springer, New York, pp 39-63

14. McVay CB Abdominal wall (1984) In: McVay (ed) Anson and McVay surgical anatomy, 6th edn.: WB Saunders Co, Philadelphia, pp 484-580

15. Skandalakis JE, Gray SW, Skandalakis LJ et al (1989) Surgical anatomy of the inguinal area. World J Surg 13:490-498

16. Kingsnorth AN, Skandalakis PN, Colborn GL et al (2000) Embriology, anatomy, and surgical applications of the preperitoneal space. Surg Clin North Am 80:1-24

17. Bendavid R, Howarth D (2000) Transversalis fascia rediscovered. Surg Clin North Am 80:25-33

18. Korobkin M, Silverman PM, Quint LE et al (1992) CT of the preperitoneal space: normal anatomy and fluid collections. AJR 159:933-945

19. Skandalakis LJ, Androulakis J, Colborn GL et al (2000) Obturator hernia. Embriology, anatomy, and surgical applications. Surg Clin North Am 80:71-84

20. Anson BJ, Morgan EH, McVay CB (1960) Surgical anatomy of the inguinal region based upon study of 500 body-halves. Surg Gyn Obst 111:707-725

21. Mikkelsen T, Bay-Nielsen M, Kehlet H (2000) Risk of femoral hernia after inguinal herniorraphy. Br J Surg 89:486-488 
22. Balén EM, Ferrer JV, Blázquez L et al (2000) Recurrences after prosthetic repair of inguinal hernias by Lichtenstein technique. Hernia 4:13-16

23. Chan G, Chan CK (2011) The characteristics of inguinal hernia recurrence in the modern era and the long-term outcomes after reoperation. Hernia 15:193-199

24. Eker HH, Langeveld HR, Klitsie PJ et al (2012) Randomized clinical trial of total extraperitoneal inguinal hernioplasty vs Lichtenstein repair. Arch Surg 147:256-260

25. Pélissier EP, Blum D, Ngo P, Monek O (2008) Transinguinal preperitoneal repair with the Polysoft patch: prospective evaluation of recurrence and chronic pain. Hernia 12:51-56

26. Koning GG, Koole D, de Jongh MA et al (2011) The transinguinal preperitoneal hernia correction vs Lichtenstein's technique; is TIPP top? Hernia 15:19-22

27. Koning GG, Keus F, Koeslag L et al (2012) Randomized clinical trial of chronic pain after the transinguinal preperitoneal technique compared with Lichtenstein's method for inguinal hernia repair. Br J Surg 99:1365-1373

28. Nyhus LM, Pollak R, Bombeck CT et al (1988) The preperitoneal approach and prosthetic buttress repair for recurrent hernia. The evolution of a technique. Ann Surg 208:733-737

29. Patiño JF, García-Herreros LG, Zundel N (1998) Inguinal hernia repair. The Nyhus posterior preperitoneal operation. Surg Clin North Am 78:1063-1074

30. Franneby U, Sandbloom G, Nordin P et al (2006) Risk factors for long-term pain after hernia surgery. Ann Surg 244:212-219

31. Wantz GE (1993) Testicular atrophy and chronic residual neuralgia as risks of inguinal hernioplasty. Surg Clin North Am 73:571-581

32. Mui WL, Ng CS, Fung TM (2006) Prophylactic ilioinguinal neurectomy in open inguinal hernia repair: a double-blind randomized controlled trial. Ann Surg 244:27-33 